\title{
Cytoprotective effects of molsidomine against methotrexate-induced hepatotoxicity: an experimental rat study
}

This article was published in the following Dove Press journal: Drug Design, Development and Therapy

\author{
Emine Turkmen Samdanci' \\ Mustafa Huz' \\ Onural Ozhan ${ }^{2}$ \\ Kevser Tanbek ${ }^{3}$ \\ Esra Pamukcu ${ }^{4}$ \\ Ayse Nur Akatli ${ }^{1}$ \\ Hakan Parlakpinar ${ }^{2}$ \\ 'Department of Pathology, Inonu \\ University School of Medicine, \\ Malatya, Turkey; ${ }^{2}$ Department of \\ Pharmacology, Inonu University \\ School of Medicine, Malatya, Turkey; \\ ${ }^{3}$ Department of Physiology, Inonu \\ University School of Medicine, \\ Malatya, Turkey; ${ }^{4}$ Department of \\ Statistics, Fırat University Faculty of \\ Science, Elazığ, Turkey
}

\begin{abstract}
Introduction and aim: Methotrexate (Mtx) is an antineoplastic and immunosuppressive drug that may cause hepatotoxicity, whereas molsidomine (Mol) is a vasodilating and antioxidant agent. This study aimed to investigate the potential protective effects of Mol in Mtx-induced liver toxicity in rats.
\end{abstract}

Materials and methods: Forty Wistar albino rats were equally divided into five groups: control, Mol, Mtx, Mol-Mtx, and Mtx-Mol. Following treatment, the animals were sacrificed, and liver tissue samples were histopathologically evaluated using Roening grading and Bcl-2 antibody staining. Tissue oxidants, antioxidants, and serum transaminases were measured and statistically compared across all groups.

Results: No hepatic fibrosis or steatosis was observed in any of the groups. In the Mtx group, grade 2 liver injury and score 2 Bcl-2 antibody staining were observed; however, in the Mol-Mtx group, these were lower (grade 1, score 1). There were no statistically significant differences in serum transaminase levels among groups. Malondialdehyde levels were higher in all rats that received Mtx, but no differences in myeloperoxidase levels were observed among the groups. Levels of tissue antioxidants, including superoxide dismutase, glutathione (GSH) peroxidase (GSH-Px), and reduced GSH, were significantly higher in the Mol-treated and Mol pre-treated groups. Catalase (CAT) levels were elevated in all Mol-treated groups, but only in that group were CAT levels statistically significantly higher than in the control group.

Conclusion: Our results suggest that some oxidant levels could increase following Mtx administration in the liver, possibly contributing to liver damage, whereas Mol could mitigate the histopathological and biochemical effects of hepatotoxicity. However, molecular studies are required to understand the exact mechanisms of these alterations.

Keywords: methotrexate, molsidomine, hepatotoxicity, hepatic fibrosis

\section{Introduction}

Methotrexate (Mtx) is a folic acid antagonist and cytotoxic agent that effectively inhibits cellular growth. It is used in many clinical indications, including leukemia, lymphomas, and other malignancies; autoimmune diseases, such as psoriasis and rheumatoid arthritis; and ectopic pregnancy. ${ }^{1,2}$ Mtx is typically well tolerated by patients, although its cytotoxic function also causes adverse effects on hepatic, renal, pulmonary, and hematopoietic tissues..$^{2-4}$ Although the molecular mechanism of Mtxinduced hepatotoxicity is not completely understood, rat studies have indicated that this side effect is likely related to the increasing levels of ROS, hydrogen peroxide, and hydroxyl radicals as a result of oxidative stress and lipid peroxidation, ${ }^{5}$ along with decreased levels of antioxidant defense molecules. ${ }^{4,6}$ Furthermore, it was reported
Correspondence: Emine Turkmen Samdanci

Department of Pathology, Inonu University School of Medicine,

Malatya, Turkey

Tel +905392902907

Email esamdanci@gmail.com
Drug Design, Development and Therapy 2019:13 13-21

13

Dovepress if in 0

http:

(c) (1) (5) 2019 Samdanci et al. This work is published and licensed by Dove Medical Press Limited. The full terms of this license are available at https://www.dovepress.com/terms.php (c)
hereby accept the Terms. Non-commercial uses of the work are permitted without any further permission from Dove Medical Press Limited, provided the work is properly attributed. For permission for commercial use of this work, please see paragraphs 4.2 and 5 of our Terms (https://www.dovepress.com/terms.php). 
that Mtx reduced cellular levels of glutathione (GSH), an important cytosolic antioxidant and free radical scavenger, and it increased the levels of malondialdehyde (MDA) and myeloperoxidase (MPO). ${ }^{1,4}$ Additionally, Kobayashi et $\mathrm{al}^{7}$ reported that upregulation of p53 and p21 played a significant role in the induction of hepatocyte apoptosis following administration of a single dose of Mtx in rats. Therefore, the reduction of Mtx side effects is a hot topic in medicine; however, very few drugs are known, which reverse the Mtx-induced oxidative damage in liver tissue.

Molsidomine (Mol), a vasodilator agent, has been used in the treatment of stable angina pectoris. ${ }^{6,8}$ It is a nitric oxide (NO) donor and a pro-drug that is enzymatically decarboxylated by the liver to the active molecule. In addition to its vasodilating effect, Mol has also been shown to have antioxidant and anti-inflammatory effects in the context of tissue damage. ${ }^{9}{ }^{10}$ Furthermore, Mol has been shown to successfully prevent oxidative stress-induced tissue injuries, such as cisplatin-induced hepatotoxicity ${ }^{11}$ and cyclosporineand iron-induced nephrotoxicities. ${ }^{12,13}$ However, there are almost no data on the possible protective effects of $\mathrm{Mol}$ on the hepatic tissue damage caused by Mtx.

In this study, a rat model was designed to assess whether Mol had any protective effects against oxidative stress injury, which was caused by acute Mtx-induced hepatotoxicity. For this purpose, histopathological changes and levels of tissue antioxidants and serum transaminases were measured in Mtx-administered animals with or without Mol treatment. We believe that the results of this study will play an important role in demonstrating that it may be possible to reduce liver toxicity, one of the most important side effects limiting the effective use of an indispensable cytotoxic agent, such as Mtx, with a drug with relatively few side effects, such as Mol.

\section{Materials and methods}

\section{Animals and experimental procedure}

The experimental protocol for the present study was approved by the Ethics Committee on Animal Research of Inonu University (Reference Number: 2014/A-63), and the Guidelines for Animal Research from the National Institute of Health were followed in all experimental procedures. Forty male, post-pubertal (10-12 weeks) Wistar albino rats weighing 350-450 g were obtained from the Inonu University Laboratory Animal Research Center. We did not use the female rats in the experiments to avoid the interference of the study results with the changing hormones of the animals, and we could not use the animals from both sexes due to the limited financial source. The animals were housed at $22^{\circ} \mathrm{C} \pm 2{ }^{\circ} \mathrm{C}$ and $60 \% \pm 5 \%$ relative humidity in wire bottom colony cages (four rats/cage) with a 12-hour light/dark cycle (7:00 am-7:00 pm) and fed standard rat chow and tap water ad libitum. The animals were divided into five groups according to their experimental treatment as follows: the control group $(n=8)$ received only physiological serum; the Mol group ( $n=8)$ was treated by intraperitoneal (i.p.) injection with $4 \mathrm{mg} / \mathrm{kg} /$ day Mol (molsidomine, Sigma Chemical Co., St Louis, MO, USA) for seven consecutive days; the Mtx group $(n=8)$ received a single i.p. injection of 20 mg/kg Mtx (Mtx DBL, 500 mg/20 mL, Koçak Farma, Istanbul, Turkey); the Mol plus Mtx group (Mol-Mtx) $(n=8)$ received a single i.p. dose of $\mathrm{Mol}$ ( $4 \mathrm{mg} / \mathrm{kg} /$ day) for seven consecutive days following a single-dose i.p. injection of $\operatorname{Mtx}(20 \mathrm{mg} / \mathrm{kg} /$ day); and the Mtx plus Mol group (Mtx-Mol) $(n=8)$ received a single i.p. dose of Mtx (20 mg/kg/day) for seven consecutive days following a single-dose i.p. injection of $\mathrm{Mol}$ ( $4 \mathrm{mg} / \mathrm{kg} / \mathrm{day})$. At the end of the experimental procedure, all rats were sacrificed with high doses of a ketamine (100 mg/kg i.p.) and xylazine (10 mg/kg i.p.) anesthesia mixture. The entire liver was excised and split; one half was fixed in formalin $(10 \%)$ and embedded in paraffin for subsequent use in histopathological analysis, and the other half was stored at $-80^{\circ} \mathrm{C}$ for biochemical analysis. Blood samples were obtained from the inferior vena cava for serum biochemical analysis.

\section{Histopathological examination}

Liver sections ( $4 \mu \mathrm{m}$ ) were stained with H\&E and Masson's trichrome (for hepatic fibrosis). Sections were stained with Bcl-2 antibody (Novus Biologicals, LLC 8100, catalog number: NB100-56101 Southpark Way, A-8 Littleton, CO 80120 , US) on poly-L-lysine-coated slides in a Ventana Benchmark XT immunohistochemical staining device (Ventana Medical Systems, Roche Group, Tucson, AZ, USA). All sections were examined using a light microscope (Olympus BX53, Tokyo, Japan).

Mtx-induced hepatic injury was histomorphologically evaluated according to the Roenigk classification ${ }^{14}$ as follows: grade 1: normal tissue, no/mild fatty change, no/mild nuclear pleomorphism, no fibrosis, and mild portal inflammation; grade 2: moderate/severe fatty changes, moderate/severe nuclear pleomorphism, no fibrosis, and moderate/severe portal inflammation; grade 3a: mild fibrosis, portal fibrotic septa extending into the lobuli, and portal tract enlargement; grade 3b: moderate/severe fibrosis; and grade 4: cirrhosis, regenerating noduli, and bridging of the portal tracts. ${ }^{15}$ 
Bcl-2 antibody stained sections were semiquantitatively scored and evaluated according to the Rappaport model. ${ }^{11}$ In this model, three zones were defined according to the blood flow as follows: zone 1 (periportal area), zone 2 (midzonal area), and zone 3 (centrilobular area). We scored the Bcl-2 antibody staining as follows: score 0 : no staining with Bcl-2 antibody; score 1: positive staining with Bcl-2 antibody of 1-2 rows of hepatocytes within zone 3 ; score 2 : score 1 plus scattered positive Bcl-2 stained hepatocytes; score 3: positive staining with Bcl-2 antibody of zone 1 and zone 2 hepatocytes.

\section{Biochemical analyses}

In this study, both before and after Mtx administration, the following tissue oxidants and antioxidants were analyzed: MDA, MPO, superoxide dismutase (SOD), catalase (CAT), GSH peroxidase (GSH-Px), and reduced GSH. In addition, aspartate amino transferase (AST) and alanine amino transferase (ALT) levels were measured in serum samples.

Blood samples obtained from the inferior vena cava were extracted to evaluate serum levels of AST and ALT using an Abbott C1600 Autoanalyzer (Abbott, Abbott Park, IL, USA). The MDA contents of the homogenates were determined spectrophotometrically by measuring the presence of thiobarbituric acid reactive substances (TBARS). ${ }^{16}$ The amount of lipid peroxides was calculated as TBARS of lipid peroxidation. The results were calculated in $\mathrm{nmol} / \mathrm{g}$ tissue according to a prepared standard graph, which was prepared using the measurements of standard solutions (1,1,3,3-tetramethoxypropane).

Total SOD activity was determined using the method of Sun et al, ${ }^{17}$ which involves the inhibition of nitro blue tetrazolium (NBT) reduction by employing the xanthine-xanthine oxidase system as a superoxide generator. One unit of SOD was defined as the enzyme amount, causing 50\% inhibition in the NBT reduction rate. SOD activity is provided in $\mathrm{U} / \mathrm{mg}$ of protein.

GSH-Px activity was measured using Paglia and Valentine's method. ${ }^{18}$ Via an enzymatic reaction in a tube containing nicotinamide adenine dinucleotide phosphate, GSH, and sodium azide, GSH reductase was initiated by the addition of $\mathrm{H}_{2} \mathrm{O}_{2}$, and the change in absorbance was observed by a spectrophotometer at $340 \mathrm{~nm}$. The activity is expressed in $\mathrm{U} / \mathrm{g}$ of protein.

The reduced GSH concentration in homogenate was measured spectrophotometrically according to Ellman's method. ${ }^{19}$ Reduction in GSH content in ileum tissue as non-protein sulfhydryls was analyzed using the described method. ${ }^{19}$ Absorbance values were extrapolated from a GSH standard curve and expressed as reduced GSH $(\mu \mathrm{mol} / \mathrm{g}$ of tissue).

CAT activity was determined according to Aebi's method. ${ }^{20}$ This assay is based on the determination of the constant rate (k, s-1) or the $\mathrm{H}_{2} \mathrm{O}_{2}$ decomposition rate at $240 \mathrm{~nm}$. Results are expressed in $\mathrm{k} / \mathrm{g}$ of protein.

The MPO level in tissues was spectrophotometrically assayed using a Biotek HT Synergy Gen 5 software immunoplate reader and a commercial Rat MPO ELISA kit (Shanghai Sunred Biological Technology Co., Ltd., Shanghai, China, Catalog No: 201-11-0575). MPO value was calculated as $\mathrm{ng} / \mathrm{mL}$ by calibrating using standard measurements prepared in the kit.

\section{Statistical analyses}

Data were analyzed using IBM SPSS for Windows version 22.0 (SPSS Inc., Chicago, IL, USA). Descriptive statistics of the dataset are expressed as medians (min. value-max. value). The Kruskal-Wallis H test was used for group comparisons, and the post hoc Dunn test was then used for multicomparisons. $P$-values $<0.05$ were regarded as statistically significant and are provided in bold type in Tables 1 and 2.

\section{Ethical approval and consent to participate}

This study was approved by the Ethics Committee on Animal Research of Inonu University (Reference Number: 2014/ A-63). No human consent was required for this study.

\section{Results}

\section{Body and liver weights}

No animals died during the active experimental period. No body weight differences were observed before or after

Table I The level of serum transaminases measured in the rat groups

\begin{tabular}{|c|c|c|c|c|c|c|c|}
\hline Transaminases & Control $(n=8)$ & $\begin{array}{l}\text { Mol } \\
(n=8)\end{array}$ & $\begin{array}{l}\text { Mtx }+ \text { Mol } \\
(n=8)\end{array}$ & Mol + Mtx $(n=8)$ & $\operatorname{Mtx}(n=8)$ & $P^{*}$ & $\mathbf{P} * *$ \\
\hline ALT (U/L) median (min-max) & $93(78-137)$ & $92(57-126)$ & $86(35-223)$ & $81(35-118)$ & $79,5(42-128)$ & 0.392 & - \\
\hline AST (U/L) median (min-max) & $209.5(154-285)$ & $242(155-379)$ & $164(70-419)$ & $163.5(108-203)$ & $191(96-296)$ & 0.106 & - \\
\hline
\end{tabular}

Notes: $P *$ : $P$-values for Kruskal-Wallis $\mathrm{H}$ Test. $P * *$ : $P$-values for pairwise comparisons.

Abbreviations: ALT, alanine amino transferase; AST, aspartate amino transferase; Mol, molsidomine; Mtx, methotrexate. 


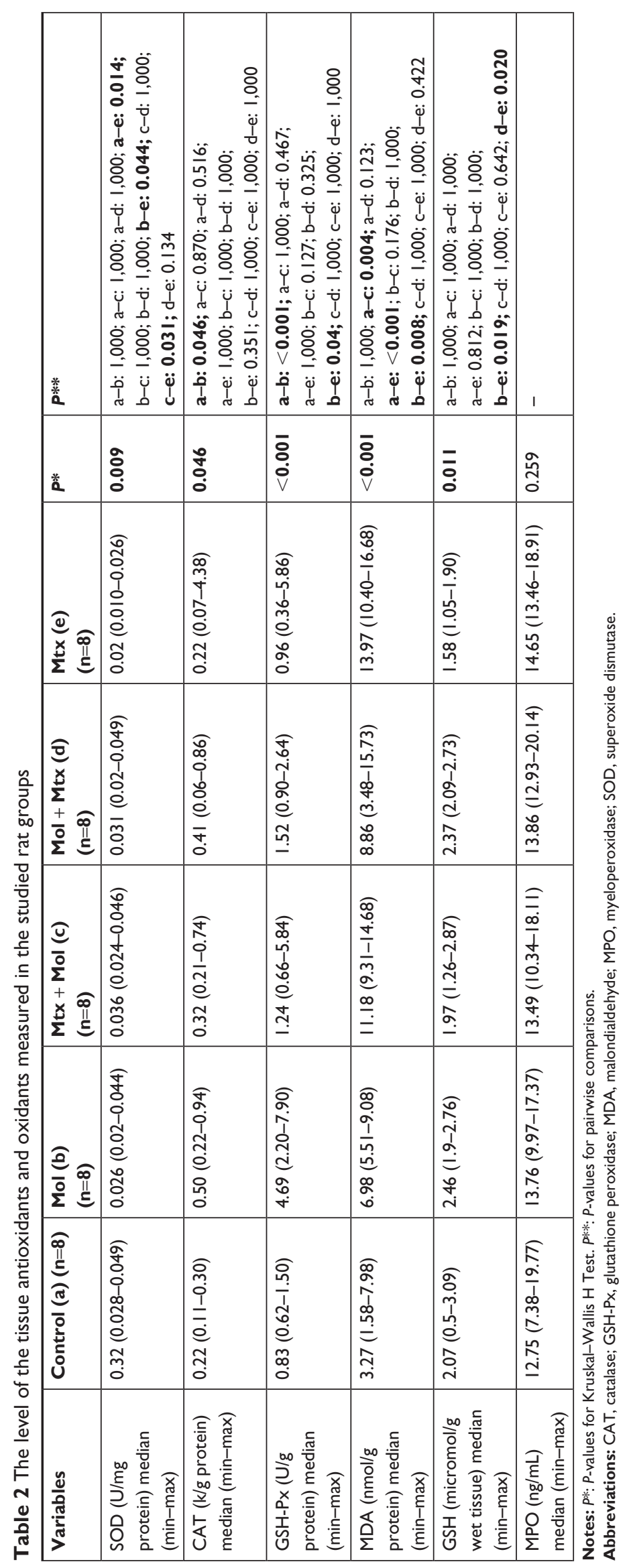


the experiments among all groups. Furthermore, there were no significant differences in the liver weights of the groups after euthanasia (data not shown). We thought that it might be due to the fact that Mtx-induced liver injury developed in the animals was independent of body and liver weight changes.

\section{Histopathological findings}

In the control group, normal liver histology was observed. No hepatic fibrosis was observed in any of the groups with Masson's trichrome staining, and steatosis did not occur (Figure 1).

The histomorphological findings in the Mol and Mtx groups were similar and included mild bile duct proliferation and moderate chronic inflammation associated with eosinophil leukocytes. Scattered single cell necrosis (apoptosis) and vacuolar degeneration were present in the pericentral area and in the lobular hepatocytes of these groups. Compared with the remaining three study groups, decreased inflammation and bile duct proliferation were observed in the Mol-Mtx group. Morphological findings in the Mtx-Mol group were similar to those in the Mtx and Mol groups (Figure 2).

No immunostaining was observed with Bcl-2 antibody in the control group (Figure 1). In the Mol group, score 1 immunostaining was recorded with Bcl-2 antibody. Score 2 immunostaining was detected in the pericentral and lobular hepatocytes in both the Mtx and Mtx-Mol groups. In the Mol-Mtx group, there was score $1 \mathrm{Bcl}-2$ immunostaining in the pericentral hepatocytes (Figure 2). The results of the histopathological and immunohistochemical stainings are summarized in Table 3.

\section{Biochemical findings}

No statistically significant differences were observed in the serum levels of AST and ALT among the groups in this study; the results are presented in Table 1.

A significantly lower concentration of SOD was observed in the Mtx group than in all other study groups (control, Mol,
Mtx-Mol, and Mol-Mtx). The CAT levels were significantly higher in the Mol group than in the control group, although no further differences were detected among the other groups. GSH-Px levels were significantly higher in the Mol group than in the control and Mtx groups. Additionally, GSH was significantly higher in the Mol and Mol-Mtx groups than in the Mtx group. MDA levels were higher in all Mtxadministered groups than in both control and Mol groups; however, there was no significant difference in MDA levels between the control and Mol groups. Moreover, no significant differences in MPO level were present among the groups; the results are presented in Table 2 .

\section{Discussion}

In the present study, the possible protective effects of Mol in Mtx-induced liver toxicity were assessed. As such, we measured alterations in some tissue oxidants and antioxidants, as well as the serum markers in the rats receiving Mol, Mtx, and Mol and Mtx combinations. Our results indicate that Mol-only and Mtx-only groups exhibited histomorphological changes, including vacuolar degeneration, chronic portal inflammation with eosinophils, mild-to-moderate bile duct proliferation, and noncaseating granulomas in the liver, all changes consistent with the effects of Mtx. We also observed lowered Mtx-mediated liver toxicity in rats that received Mol pre-treatment.

Lipid peroxidation is an important oxidative stress mechanism in Mtx-induced liver toxicity. ${ }^{21}$ Because MDA has been reported as an end-product of lipid peroxidation, it has been used as a marker to indicate the level of tissue damage. ${ }^{22-24}$ We observed significantly elevated levels of MDA in the Mtx-only and Mtx-Mol groups. We determined that MDA levels decreased following Mol administration in this study, which is in accordance with the results of previous studies on the antioxidant activity of Mol. ${ }^{25}$ Furthermore, we observed apoptosis and vacuolar degeneration in rat hepatocytes, which were likely a result of lipid peroxidation induced by Mtx.
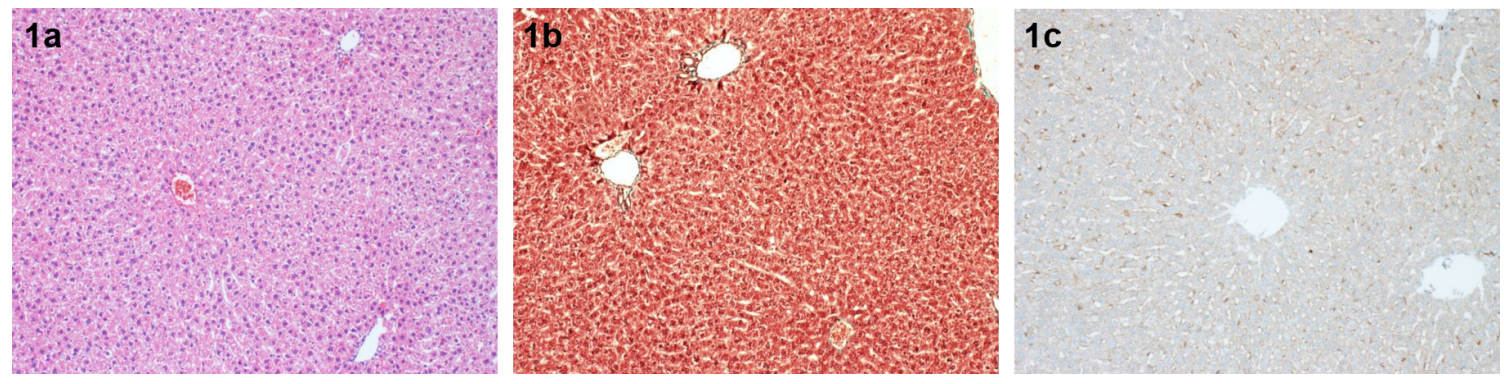

Figure I Control group Ia: Normal liver histology $(H \& E \times I 00)$, Ib: Normal fibrous tissue in the portal area (Masson's trichrome $\times$ I00), Ic: Negative immunohistochemical staining (Bcl-2 antibody $\times 100)$. 

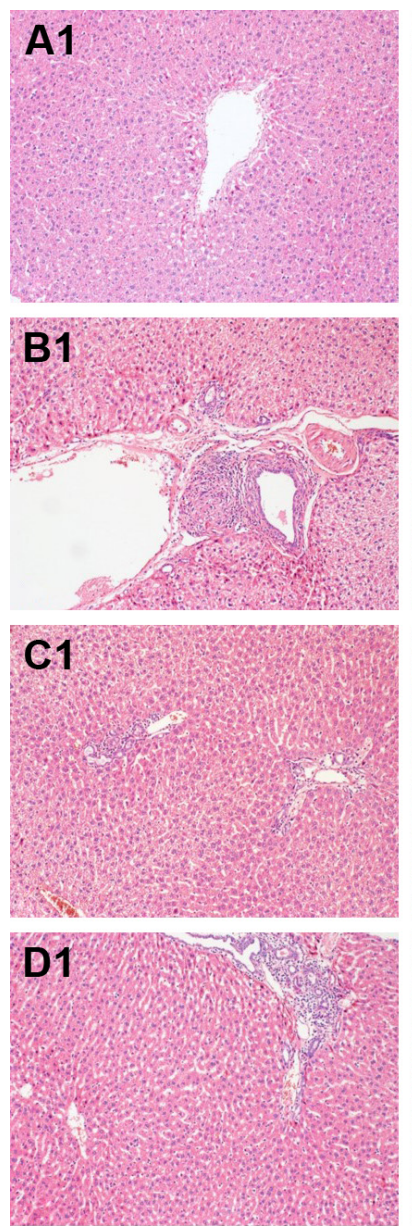
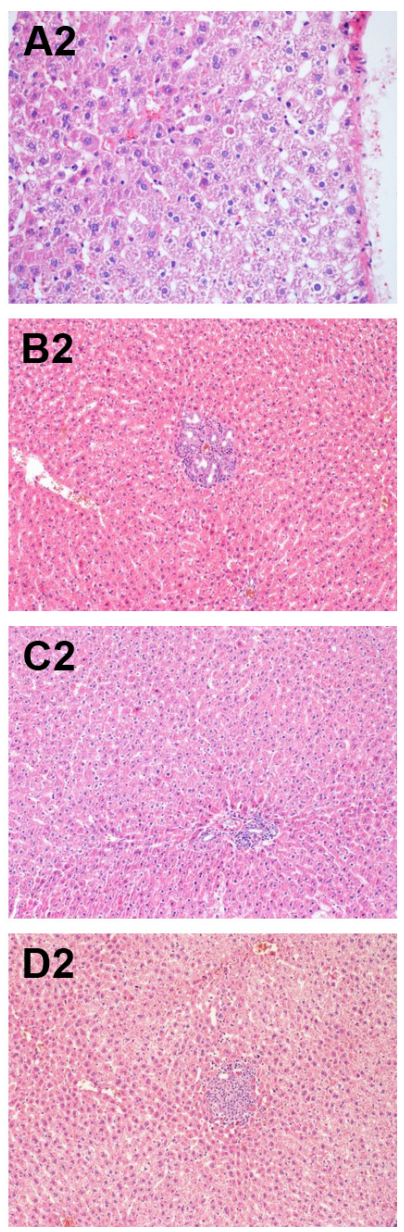
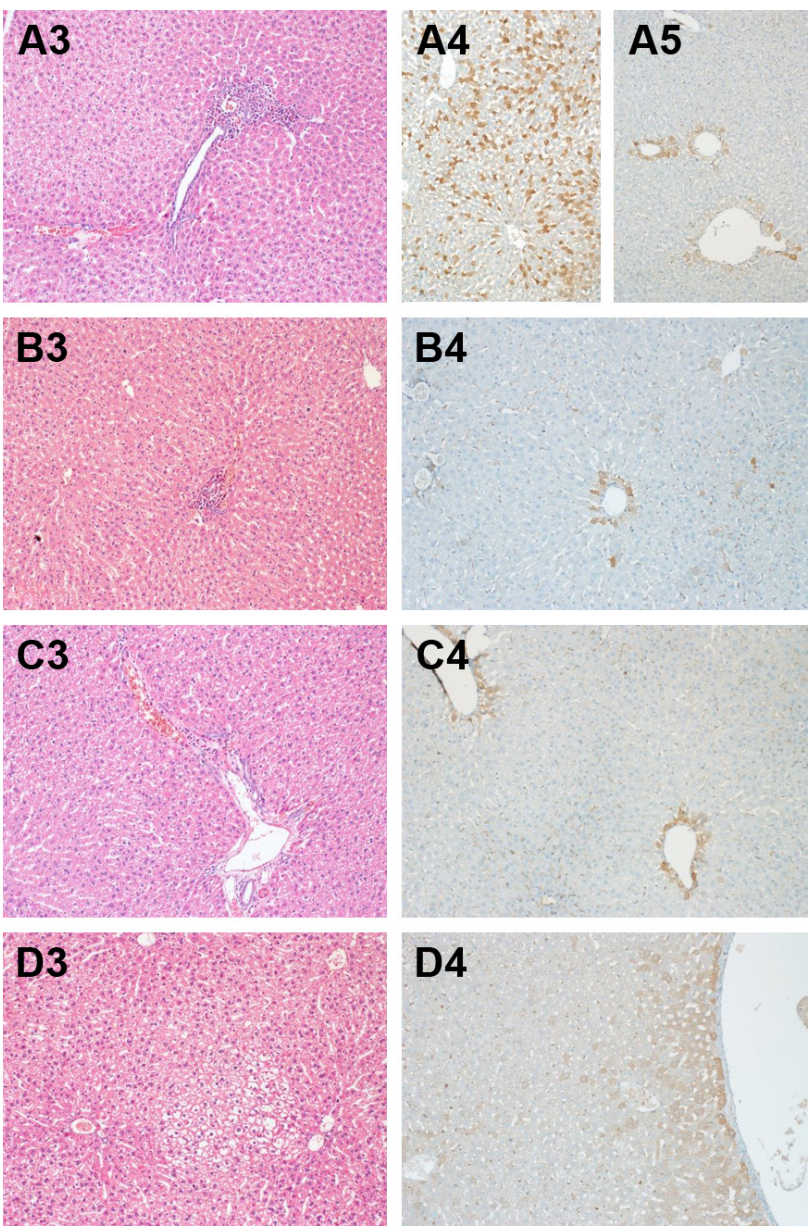

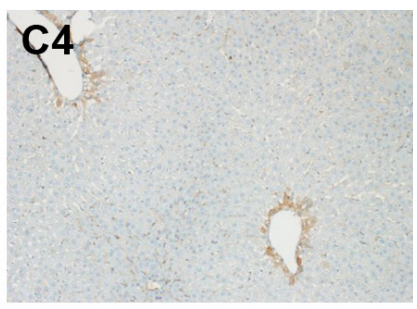

D4

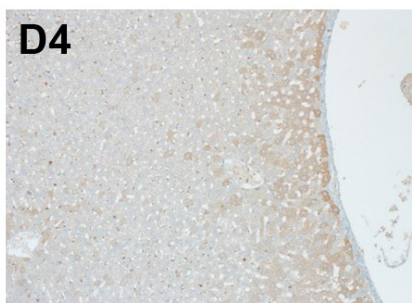

Figure 2 (A) Mtx group; I: vacuolar degeneration in pericentral hepatocytes (H\&E $\times 100)$, 2: an apoptotic hepatocyte (H\&E $\times 100)$, 3: grade 2 portal inflammation (H\&E $\times 100)$, 4: score 2 positive immunohistochemical staining with Bcl-2 antibody in hepatocytes of the lobular area and 5: pericentral zone (Bcl-2 antibody $\times 100)$. (B) Mol group; I: granuloma formation in the portal area $(H \& E \times 100)$, 2: mild bile duct proliferation $(H \& E \times I 00)$, 3: grade I portal inflammation (H\&E $\times 100)$, 4: score I positive immunohistochemical staining with $\mathrm{Bcl}-2$ antibody in hepatocytes of the pericentral zone $(\mathrm{Bcl}-2$ antibody $\times \mathrm{I00})$. (C) Mol-Mtx group; I: mild bile duct proliferation ( $\mathrm{H} \& \mathrm{E}$ $\times 100)$, 2: grade I portal inflammation $(H \& E \times 100)$, 3: minimal portal inflammation $(H \& E \times 100)$, 4: score I positive immunohistochemical staining with Bcl-2 antibody in hepatocytes of the pericentral zone (Bcl-2 antibody $\times$ I00). (D) Mtx-Mol group; I: moderate bile duct proliferation and grade 2 portal inflammation (H\&E $\times$ I00), 2: granuloma formation in the lobular area $(\mathrm{H} \& \mathrm{E} \times 100)$, 3: vacuolar degeneration in lobular hepatocytes $(\mathrm{H} \& \mathrm{E} \times 100)$, 4: score 2 positive immunohistochemical staining with Bcl-2 antibodies in hepatocytes of the pericentral zone and lobular area $(\mathrm{Bcl}-2$ antibody $\times 100)$.

Abbreviations: Mol, molsidomine; Mtx, methotrexate.

MPO is a peroxidase enzyme that is stored in azurophilic granules of neutrophil leucocytes and macrophages and released into extracellular areas during an acute inflammatory process. ${ }^{26}$ Some authors have reported that MPO could

Table 3 Histopathological findings in the liver tissue specimens of the studied rat groups

\begin{tabular}{l|l|l}
\hline Rat groups & $\begin{array}{l}\text { Roenigk } \\
\text { classification }\end{array}$ & $\begin{array}{l}\text { Bcl-2 antibody } \\
\text { score }\end{array}$ \\
\hline Control & Grade I (8/8) & Score 0 (8/8) \\
Mtx & Grade 2 (8/8) & Score 2 (8/8) \\
Mol-Mtx & Grade I (5/8) & Score I (5/8) \\
Mtx-Mol & Grade 2 (8/8) & Score 2 (7/8) \\
Mol & Grade 2 (8/8) & Score I (8/8) \\
\hline
\end{tabular}

Notes: aln the Mol-Mtx group, the remaining $3 / 8$ rats were in the score 2 (Roenigk Classification). IIn the Mtx-Mol group, the remaining I/8 rat was in Bcl-2 antibody score I.

Abbreviations: Mol, molsidomine; Mtx, methotrexate. be used as a marker to indicate Mtx-mediated oxidative liver injury associated with centrilobular necrosis, apoptotic bodies, and inflammation. ${ }^{27}$ However, in contrast to the results of the previous studies reporting increased MPO levels in rat livers following Mtx treatment, ${ }^{28,29}$ the present study did not detect any significant increase in MPO levels, even in the Mtx-only group. This was possibly due to the absence of neutrophil leukocytes and macrophage infiltration in the livers of the rats, although mild-to-moderate chronic inflammation was observed.

GSH is an antioxidant that is produced in many kinds of cells, including animal, plant, and bacteria cells, whereas GSH-Px is a selenium-dependent GSH possessing a catalytic center containing selenium in the form of selenocysteine; together with GSH, it catalyzes the reduction of hydrogen peroxide and lipid peroxides. ${ }^{30}$ Previous studies have 
highlighted the many roles of GSH, including antioxidant defense (ROS scavenging), detoxification, modulation of redox-regulated signal transduction, regulation of cell proliferation, regulation of immune response, and regulation of leukotriene and prostaglandin metabolism. ${ }^{31}$ In the present study, we observed that GSH and GSH-Px levels were higher in the Mol and Mol-Mtx groups than in the control and Mtx groups. Interestingly, in the Mol group, GSH-Px levels were statistically higher than in the control group. The aforementioned findings suggest that administration of Mol only and Mol pre-treatment could exhibit an antioxidant effect by increasing tissue GSH and GSH-Px levels in Mtx-induced hepatotoxicity.

SOD is one of the major antioxidant defense systems against oxygen radicals, and it requires catalytic metal ions (Cu or $\mathrm{Mn}$ ) for activation. Superoxide anions are dismutated by SOD to hydrogen peroxide, which is then catalyzed to $\mathrm{H}_{2} \mathrm{O}$ by CAT, peroxiredoxins, or GSH-Px. ${ }^{32}$ We observed that SOD levels were significantly lower in the Mtx group than in all other groups in this study. These findings suggest that Mtx-mediated oxidative damage in the liver possibly occurs by reducing tissue SOD; as such, Mol treatment may improve this injury by increasing the SOD levels. Similarly, elevated CAT levels were observed in all Mol-treated groups, although CAT levels were only elevated to a statistically significant degree in the Mol-only group. Notably, CAT levels were equal in the control and Mtx groups. Therefore, CAT could potentially be an unsuitable marker for Mtx-induced tissue damage in the liver. These findings suggest that Mol treatment may contribute to expanding the liver's antioxidant capacity by increasing CAT levels in liver tissue, whereas Mtx administration caused a decrease in the concentration of CAT to normal levels in the Mol plus Mtx-administered groups. Because CAT levels were not abnormally low in the Mtx-administered group without any Mol treatment, it is suggested that the liver can sustain normal CAT levels despite the oxidative stress produced by Mtx without requiring any external support, such as medication with Mol. However, it is apparent that further studies are required to understand the exact mechanisms of CAT response in the liver tissue to Mtx and Mol treatments.

The risk of hepatic fibrosis is $\sim 15 \%$ in rheumatologic patients, with high levels of serum transaminases that increase following the application of a standard dose $\left(10-12.5 \mathrm{mg} / \mathrm{m}^{2}\right.$ per week) of Mtx..$^{33}$ In some recent studies, the rate of liver fibrosis due to total dose or long-term use of Mtx was reported at $\sim 4 \%$, and when high-risk groups (such as patients with chronic hepatitis, diabetes mellitus, or a history of alcohol consumption) were excluded, no direct relationship was found between Mtx use and liver fibrosis. ${ }^{34,35}$ In the present study, we determined that liver fibrosis did not develop following Mtx use in rats without any preexisting risk factors for liver damage. Because liver fibrosis increasingly emerges in cases of chronic liver damage, ${ }^{36}$ we believe that liver fibrosis did not develop in our rats because Mtx was administered over a short time period.

A previous study reported that increased serum transaminase levels (AST, ALT), indicating acute hepatotoxicity, recovered to normal levels after $\sim 2$ weeks. ${ }^{37}$ No increase in the transaminase levels was observed in the present study (Table 3). However, we observed rare apoptotic cells and increased apoptosis in Bcl-2 staining. However, these increases did not show any impact on the serum levels of transaminases. Although some histopathological alterations were identified in the Mtx-administered groups, we believe that they were not significant enough to limit the use of Mtx. However, other factors should be considered prior to Mtx administration due to their potential for inducing liver injury, including chronic hepatitis, diabetes, and alcohol consumption. ${ }^{38}$

Mol has been used in the treatment of angina pectoris due to its vasodilatation activity on the vascular smooth muscles. ${ }^{39}$ However, limited information is available regarding its potential role in the protection against hepatic fibrosis. In one study, it was suggested that Mol inhibits hepatic fibrosis by increasing the production and secretion of $\mathrm{NO}$ amid decreasing levels of $\alpha$-smooth muscle actin and accumulation of collagen type-I in hepatic injury cases.$^{40}$ Nevertheless, there is a paucity of data on the antifibrotic activity of Mol in the liver.

One significant limitation of this study is the lack of experiments exploring the molecular dynamics of Mol in the improvement of Mtx-mediated liver toxicity. Such interactions can be detailed in a cell culture model. However, because hepatotoxicity is a result of complex mechanisms, including involvement of the immune system, animal studies must be performed in association with such in vitro experiments. The relatively small sample size of the included subjects may be another limitation of this study.

Animal models are routinely used to study human liver injury; however, such studies sometimes fail to recreate the etiology and even the severity of human liver pathology due to species differences. However, experimental study results must be obtained prior to human investigation(s) and human treatments. Further experimental and human studies have been planned to expand on these study results. Additionally, this possible contrasting result is not solely regarding Mtx-induced pathologies in the liver or in other tissues. 
For this reason, in the current study, we applied single dose of $20 \mathrm{mg} / \mathrm{kg}$ Mtx in rats to induce hepatotoxicity according to a method outlined in a previous study, which reported that this dosage of Mtx successfully induced oxidative liver damage in rats. ${ }^{4}$

In this study, we determined that administration of Mol was associated with histopathological improvement in Mtx-induced toxic injury in the liver, likely due to Mol's vasodilatation, antioxidant, and anti-inflammatory activities. However, further studies are needed to validate these effects and to support the clinical use of Mtx.

\section{Availability of data and material}

The datasets used and/or analyzed during the current study are available from the corresponding author upon reasonable request.

\section{Author contributions}

All authors contributed to data analysis, drafting or revising the article, gave final approval of the version to be published, and agree to be accountable for all aspects of the work.

\section{Disclosure}

The authors report no conflicts of interest in this work.

\section{References}

1. Kose E, Sapmaz HI, Sarihan E, Vardi N, Turkoz Y, Ekinci N. Beneficial effects of montelukast against methotrexate-induced liver toxicity: a biochemical and histological study. ScientificWorldJournal. 2012; 2012:987508.

2. Soliman ME. Evaluation of the possible protective role of folic acid on the liver toxicity induced experimentally by methotrexate in adult male albino rats. Egypt J Histol. 2009;32:118-128.

3. Cetin A, Kaynar L, Eser B, Karada C, Saraymen B, Öztürk A. Beneficial effects of propolis on methotrexate-induced liver injury in rats. Acta Oncologica Turcica. 2011;44:18-23.

4. Vardi N, Parlakpinar H, Cetin A, Erdogan A, Cetin Ozturk I. Protective effect of beta-carotene on methotrexate-induced oxidative liver damage. Toxicol Pathol. 2010;38(4):592-597.

5. Cure E, Kirbas A, Tumkaya L, et al. Protective effect of infliximab on methotrexate-induced liver injury in rats: unexpected drug interaction. J Cancer Res Ther. 2015;11(1):164-169.

6. Kukovetz WR, Holzmann S. Cyclic GMP as the mediator of molsidomineinduced vasodilatation. Eur J Pharmacol. 1986;122(1):103-109.

7. Kobayashi K, Terada C, Tsukamoto I. Methotrexate-induced apoptosis in hepatocytes after partial hepatectomy. Eur J Pharmacol. 2002; 438(1-2):19-24.

8. Messin R. Comparative short-term effect of once-daily molsidomine on chronic angina in general practitioners' versus cardiologists' coronary patient populations. Adv Ther. 2014;31(1):91-106.

9. Karakoc HT, Altintas R, Parlakpinar H, et al. Protective effects of molsidomine against cisplatin-induced nephrotoxicity. Adv Clin Exp Med. 2015;24(4):585-593.

10. Valdivielso JM, Blantz RC. Acute renal failure: is nitric oxide the bad guy? Antioxid Redox Signal. 2002;4(6):925-934.

11. Bentli R, Parlakpinar H, Polat A, Samdanci E, Sarihan ME, Sagir M. Molsidomine prevents cisplatin-induced hepatotoxicity. Arch Med Res. 2013;44(7):521-528.
12. Chander V, Chopra K. Effect of molsidomine and L-arginine in cyclosporine nephrotoxicity: role of nitric oxide. Toxicology. 2005; 207(3):463-474.

13. Gupta A, Sharma S, Chopra K. Reversal of iron-induced nephrotoxicity in rats by molsidomine, a nitric oxide donor. Food Chem Toxicol. 2008;46(2):537-543.

14. Roenigk HH Jr, Auerbach R, Maibach HI, Weinstein GD. Methotrexate in psoriasis: revised guidelines. J Am Acad Dermatol. 1988;19(1 Pt 1): 145-156.

15. Berends MA, Snoek J, de Jong EM, et al. Liver injury in long-term methotrexate treatment in psoriasis is relatively infrequent. Aliment Pharmacol Ther. 2006;24(5):805-811.

16. Mihara M, Uchiyama M. Determination of malonaldehyde precursor in tissues by thiobarbituric acid test. Anal Biochem. 1978;86(1): 271-278.

17. Sun Y, Oberley LW, Li Y. A simple method for clinical assay of superoxide dismutase. Clin Chem. 1988;34:497-506.

18. Paglia DE, Valentine WN. Studies on the quantitative and qualitative characterization of erythrocyte glutathione peroxidase. J Lab Clin Med. 1967;70:158-169.

19. Ellman GL. Tissue sulfhydryl groups. Arch Biochem Biophys. 1959; 82(1):70-77.

20. Aebi H, Suter H. Catalase. In: Methods of Enzymatic Analysis. 1969; 77:325.

21. Dalaklioglu S, Genc GE, Aksoy NH, Akcit F, Gumuslu S. Resveratrol ameliorates methotrexate-induced hepatotoxicity in rats via inhibition of lipid peroxidation. Hum Exp Toxicol. 2013;32(6):662-671.

22. Iraz M, Bilgic S, Samdanci E, Ozerol E, Tanbek K, Iraz M. Preventive and early therapeutic effects of $\beta$-glucan on the bleomycin-induced lung fibrosis in rats. Eur Rev Med Pharmacol Sci. 2015;19(8):1505-1506.

23. Okutan H, Savas C, Ozguner IF, Yonden Z, Eren VC, Delibas N. Lung injury after aortic occlusion-reperfusion in rats: the role of gadolinium chloride. Tohoku J Exp Med. 2004;203(4):267-273.

24. Şener G, Toklu H, Ercan F, Erkanlı G. Protective effect of beta-glucan against oxidative organ injury in a rat model of sepsis. Int Immunopharmacol. 2005;5(9):1387-1396.

25. Aldemir M, Boşnak M, Al B, Büyükbayram H, Taçyildiz I. Effects of molsidomine and lexipafant in hepatic ischaemia - reperfusion injury. Injury. 2004;35(3):232-237.

26. Loria V, Dato I, Graziani F, Biasucci LM. Myeloperoxidase: a new biomarker of inflammation in ischemic heart disease and acute coronary syndromes. Mediators Inflamm. 2008;2008(3):135625.

27. Demiryilmaz I, Sener E, Cetin N, et al. Biochemically and histopathologically comparative review of thiamine's and thiamine pyrophosphate's oxidative stress effects generated with methotrexate in rat liver. Med Sci Monit. 2012;18(12):BR475-BR481.

28. Jahovic N, Çevik H, Sehirli AO, Yeğen BC, Sener G. Melatonin prevents methotrexate-induced hepatorenal oxidative injury in rats. J Pineal Res. 2003;34(4):282-287.

29. Cetinkaya A, Bulbuloglu E, Kurutas EB, Kantarceken B. N-acetylcysteine ameliorates methotrexate-induced oxidative liver damage in rats. Med Sci Monit. 2006;12(8):BR274-BR278.

30. Pilarczyk B, Jankowiak D, Tomza-Marciniak A, et al. Selenium concentration and glutathione peroxidase (GSH-Px) activity in serum of cows at different stages of lactation. Biol Trace Elem Res. 2012;147(1-3): 91-96.

31. Sen CK. Glutathione homeostasis in response to exercise training and nutritional supplements. Mol Cell Biochem. 1999;196(1-2):31-42.

32. Fukai T, Ushio-Fukai M. Superoxide dismutases: role in redox signaling, vascular function, and diseases. Antioxid Redox Signal. 2011; 15(6):1583-1606.

33. Valentino PL, Church PC, Shah PS, et al. Hepatotoxicity caused by methotrexate therapy in children with inflammatory bowel disease: a systematic review and meta-analysis. Inflamm Bowel Dis. 2014;20(1): $47-59$.

34. Park SH, Choe JY, Kim SK. Assessment of liver fibrosis by transient elastography in rheumatoid arthritis patients treated with methotrexate. Joint Bone Spine. 2010;77(6):588-592. 
35. Quintin E, Scoazec JY, Marotte H, Miossec P. Rare incidence of methotrexate-specific lesions in liver biopsy of patients with arthritis and elevated liver enzymes. Arthritis Res Ther. 2010;12(4):R143.

36. Conway R, Carey JJ. Risk of liver disease in methotrexate treated patients. World J Hepatol. 2017;9(26):1092-1100.

37. Oguz A, Hasanoglu A, Ezgü FS, Timlioglu O, Biberoglu G, Uluoglu C. Methotrexate related acute hepatotoxicity. Gazi Medical Journal. 2002;13:69-72.

38. Laharie D, Seneschal J, Schaeverbeke T, et al. Assessment of liver fibrosis with transient elastography and FibroTest in patients treated with methotrexate for chronic inflammatory diseases: a case-control study. J Hepatol. 2010;53(6):1035-1040.
39. Gruetter CA, Barry BK, McNamara DB, Gruetter DY, Kadowitz PJ, Ignarro L. Relaxation of bovine coronary artery and activation of coronary arterial guanylate cyclase by nitric oxide, nitroprusside and a carcinogenic nitrosoamine. J Cyclic Nucleotide Res. 1979;5(3):211-224.

40. Mòdol T, Natal C, Pérez de Obanos MP, Domingo de Miguel E, Iraburu MJ, López-Zabalza MJ. Apoptosis of hepatic stellate cells mediated by specific protein nitration. Biochem Pharmacol. 2011;81(3) $451-458$.

\section{Publish your work in this journal}

Drug Design, Development and Therapy is an international, peerreviewed open-access journal that spans the spectrum of drug design and development through to clinical applications. Clinical outcomes, patient safety, and programs for the development and effective, safe, and sustained use of medicines are the features of the journal, which has also been accepted for indexing on PubMed Central. The manuscript management system is completely online and includes a very quick and fair peer-review system, which is all easy to use. Visit http://www.dovepress.com/testimonials.php to read real quotes from published authors.

Submit your manuscript here: http://www.dovepress.com/drug-design-development-and-therapy-journal 